\title{
HIGH RESOLUTION SATELLITE IMAGERY TO DETECT STRESS IN POTATO
}

\author{
Elmetwalli ${ }^{*}$, A.H., T.Z. Fouda ${ }^{* *}$ and E. Y. Ali ${ }^{* * * *}$
}

\begin{abstract}
Proper application rate of water and nitrogen fertilization are crucial factors for having the maximum and high quality of potato tuber. Mapping and detecting stress at both local and regional scales by remote sensing are very important in site specific management. This work aimed to assess the ability of high spatial resolution remote sensing imagery to detect stress in potato in South-Tripoli, Libya. A field experiment was conducted to investigate the response of potato to water and nitrogen deficiency. A GeoEye-1 satellite imagery was planned to be acquired at the flowering stage of potato to assess the potential of the remote detection of stress in potato. Ground reference data including soil samples, vegetation samples, water samples, chlorophyll estimates, and GPS coordinates were collected. The filed work was timed to coincide with the acquisition of GeoEye-1 satellite imagery $\left(21^{\text {st }}\right.$ November, 2010). The results demonstrated that the GeoEye-1 image successfully detected stress within field and local scales, and therefore can be a robust tool in site specific management. A strong linear relation between $R V I$ and NDVI derived from satellite data and potato tuber yield $(r=0.77)$. Strong correlations were also found between chlorophyll content of potato and NDVI derived from the $21^{\text {st }}$ November image ( $r=$ 0.76). The results further showed that MDC is an effective classification algorithm for differentiating different crops within the study area.
\end{abstract}

\section{INTRODUCTION}

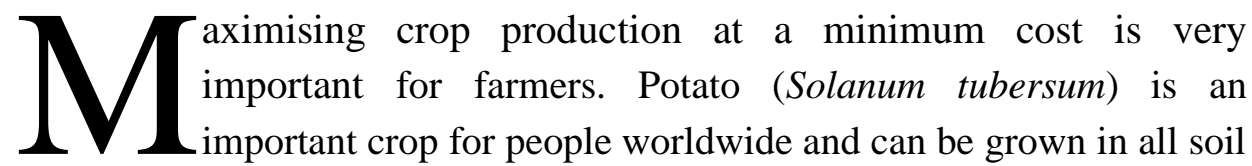
types. Water and nitrogen deficit greatly affect potato crop yield and quality.

\footnotetext{
* Lec. of Agric. Eng. Dept., Fac. of Agric., Tanta U.

** Prof., of Agric. Eng. Dept., Fac. of Agric., Tanta U.

**** Postgraduate student, Fac. of Agric., Tanta U.
} 
The potato crop evapotranspiration vary from 30 to $70 \mathrm{~cm}$ depending on the environment (Shock and Feibert, 2000). King et al. (2003) tested the effect of irrigation regime (60 and $80 \%$ of crop water requirements) on potato tuber yield (var. Russet Burbank). They reported that the total yield of potato decreased fundamentally when deficit irrigation was applied during early mid and mid late bulking. Patel and Rajput (2007) investigated the effect of drip line depth $(5,10,15$, and $20 \mathrm{~cm})$ and watering level (100, 80 and 60\% ETc) on potato yield and concluded that potato yield was higher with subsurface treatments than surface treatments and maximum yield was obtained when placing drip line at 10 $\mathrm{cm}$ depth. They also found that potato yield decreased with decreasing amount of irrigation water. Other studies investigated the effect of nitrogen fertilization on potato productivity. For example, Zvomuya et al. (2003) reported that nitrogen deficiency can substantially reduce yield, whereas excessive $\mathrm{N}$ application can delay tuber maturity and increase the nitrate contamination of surface and ground water. Mapping and predicting yield at an early growth stage is therefore essential for farmers to take decisions to improve their agricultural practices. Monitoring plant status by means of remotely sensed data will enable farmers to maintain optimal levels of soil moisture and nutrients and avoid overuse of different fertilizers, which may contaminate soil and water. It is therefore obvious that using satellite imagery could be a reliable technique in site specific management. The capabilities of new satellite sensor technology providing higher resolution (e.g. GeoEye-1 and SPOT sensors) can perhaps provide a useful tool in precision farming. GeoEye-1 and SPOT sensors and other high spatial satellite imagery have significantly narrowed the gap in spatial resolution between satellite and airborn imagery (Yang et al., 2006a). The advantage of most of these satellites is the revisit period (1-3 days), which was difficult to be accomplished with many other satellite systems (Moran, 2000). The green, red and NIR of QuickBird imagery are important for discriminating $\mathrm{N}$ deficiency and differences between nutrient and water deficit within fields (Yoder and Pettigrew-Crosby,1995). Some researchers used QuickBird satellite images for detecting biochemical and biophysical properties in crops (Wu et al., 2007a; Elmetwalli, et al., 2010). Yang et al. (2006a and 
2006b) investigated the potential of QuickBird satellite images to predict and map cotton and grain sorghum yield patterns. They established strong correlations between vegetation indices derived from QuickBird images and both crop yields. Recently, hyperspectral satellite images such as Hyperion have been used in monitoring vegetation; this satellite has more than 200 spectral bands, which enable the construction of effective continuous spectra for every pixel in the scene. This will enable researchers to develop new vegetation indices for detecting stress in crops and facilitate the process of distinguishing different sources of stress in crops. Bannari et al. (2008) developed several spectral indices to quantify chlorophyll concentration of wheat crops at both the canopy and the leaf scales using remotely sensed data.

The specific objectives of this study were to:

(1) Evaluate the efficiency of classification algorithms to map different crop types (2) Having mapped individual crop types through remote sensing, predict potato biophysical and biochemical properties through remotely sensed data and (3) choose the optimum vegetation index to predict potato tuber yield and chlorophyll content of potato.

\section{MATERIAL AND METHODS}

\section{Study site}

The experimental site is located in south Tripoli, Libya (latitude of $32^{\circ}$ $42^{\prime} 25^{\prime \prime}$ and longitude of $\left.12^{\circ} 52^{\prime} 16^{\prime \prime}\right)$. To have a range of stress levels in the experiment, the plants were subjected to different levels of watering and nitrogen fertilization. 12 different treatments were used to subject plants to different levels of watering and nitrogen deficiency stress including: four watering levels of 700, 630, 525 and $350 \mathrm{~mm}$ and three nitrogen fertilization rates of 0,50 and $200 \mathrm{~kg} / \mathrm{ha}$ and different combinations of both watering and nitrogen levels were also used To extrapolate the results, some other locations in the study area were chosen to collect ground reference data. The soil at these sites is a sandy loam with low concentration of nitrogen. The majority of the fields within the study area use sprinkler irrigation with a few farms irrigated by trickle irrigation, especially fields cultivated with trees. The weather in this area is characterised by very hot summers and mild winters. 


\section{.Chlorophyll determination}

Chlorophyll content was measured as many as possible during field work. A hand-held SPAD 502 chlorophyll meter (Minolta, Osaka, Japan) was used to measure chlorophyll. The SPAD gives a relative measure of chlorophyll (dimensionless). Apical leaves were chosen to measure the chlorophyll since they are the first part of plants to reflect solar energy. Some apical leaves were sampled for the laboratory determination of chlorophyll using spectrophotometer.

\section{Remote sensing data acquisition and analysis}

One SPOT image was acquired on $17^{\text {th }}$ September which was too early for the growing season. On $21^{\text {st }}$ November, a GeoEye-1 multispectral image was acquired covering potato and different crops in the study area in 2010 growing season. GeoEye-1 satellite is a high spatial resolution satellite comprises four multi spectral bands (blue, green, red and nearinfrared) of $2 \mathrm{~m}$ spatial resolution. The GeoEye-1 image of potato fields was acquired at 09:54 h GMT on $21^{\text {st }}$ November 2010 for the study area. Some more details about the technical specifications of the acquired image are listed in Table 1. The image was geo-corrected using image to image technique and atmospherically corrected using the dark pixel method (Elmetwalli et al., 2010). Following the geo-correction and atmospheric correction, the image was classified using both unsupervised classification (k-means) and supervised classification (MDC) to identify potato and other crops in each image. The classification methods were evaluated using a confusion matrix which derived for both k-means and MD of the GeoEye-1 image. In supervised algorithm, a validation dataset, which was independent from the training dataset, was created manually which composed at least 1500 pixels for each class. The results of the confusion matrix include the overall accuracy, the classification accuracy for each class, producer's and user's accuracy. The mean values of reflectance at different regions of the spectrum (blue, green, red and near-infrared) were derived from the corrected image using ENVI v 4.7 software then some broad band vegetation indices were calculated. The tested vegetation indices were related to different crop properties. Ten commonly used broad band vegetation indices were derived from 
satellite imagery to assess the ability of remotely sensed data to detect stress in potato and calculated as follows.

- Normalized Difference Vegetation Index $(\mathrm{NDVI})=(\mathrm{NIR}-\mathrm{Red}) /(\mathrm{NIR}+\mathrm{Red})$

- Ratio Vegetation Index (RVI) = NIR/Red

- Green Normalized Difference Vegetation Index (GNDVI) = (NIRgreen $) /(\mathrm{NIR}+$ green $)$

- $\quad$ Specific Leaf Aea Vegetation Index (SLAVI) = NIR/(Red+NIR)

- Soil Adjusted Vegetation Index $(\mathrm{SAVI})=[(\mathrm{NIR}-\mathrm{Red}) /(\mathrm{NIR}+\mathrm{Red}+\mathrm{L})]^{*}(1+\mathrm{L})$

- Difference Vegetation Index (DVI) = NIR-Red

- Vegetation Index One = NIR/(green-1)

- Renormalized Difference Vegetation Index $(\mathrm{RDVI})=\sqrt{N D V I \times D V I}$

- Stress Index (SI) = Red/NIR

- Infrared Percentage Vegetation Index = NIR/(NIR+Red)

Table 1 Technical characteristics of GeoEye-1 image of potato fields acquired on $21^{\text {st }}$ November 2010 in south Tripoli, Libya

\begin{tabular}{lc}
\hline & $\mathbf{2 1}^{\text {st }}$ November image \\
\hline Satellite & GeoEye-1 \\
Acquisition date & $2010-21-11$ \\
Acquisition time & $09: 54$ \\
Cloud cover & $0 \%$ \\
Off nadir angle & $13^{\circ}$ \\
Target azimuth angle & $162.43^{\circ}$ \\
Spectral bands & 4 \\
Environmental quality & $100 \%$ \\
Centre location & Lat/Lon $32.71^{\circ} / 12.87^{\circ}$ \\
\hline
\end{tabular}

\section{Statistical analysis}

Data were checked for normality using Anderson-Darling method with 95\% significance level. The Pearson Product Moment correlation coefficient was used to test the association between different vegetation indices and crop properties and to identify optimum vegetation indices for predicting potato properties. Simple linear and multiple regression analyses were used to derive regression equations to the retrieval of tuber yield under moisture and nitrogen deficiency. 


\section{RESULTS AND DISCUSSIONS}

\section{Identifying different crops in the study area}

Minimum Distance (MD) supervised and K-means unsupervised algorithms were used to identify different crops within the study area. Both algorithms were run on the $21^{\text {st }}$ November GeoEye- 1 image using ENVI v4.7. Figure 1 shows different crops using MD algorithm. The classification produced three distinct crops (potato, clover and citrus) and one more class (bare soil). The results of the confusion matrix showed that the overall accuracy of the k-means classification was $86.15 \%$. The classification accuracy varied for identifying different classes ranging from $66.83 \%$ (for citrus) to $92.53 \%$ (for bare soil). The classification accuracy for citrus, potato and clover were 66.83, 92.24 and $70.37 \%$ respectively (Table 2). The low classification accuracy for identifying citrus may be a result of spectral confusion between citrus and clover since most farmers grow clover in citrus fields to feed animals and to have the maximum income from the area unit. However, the k-means produced high classification accuracy it might produce too many misclassified pixels.

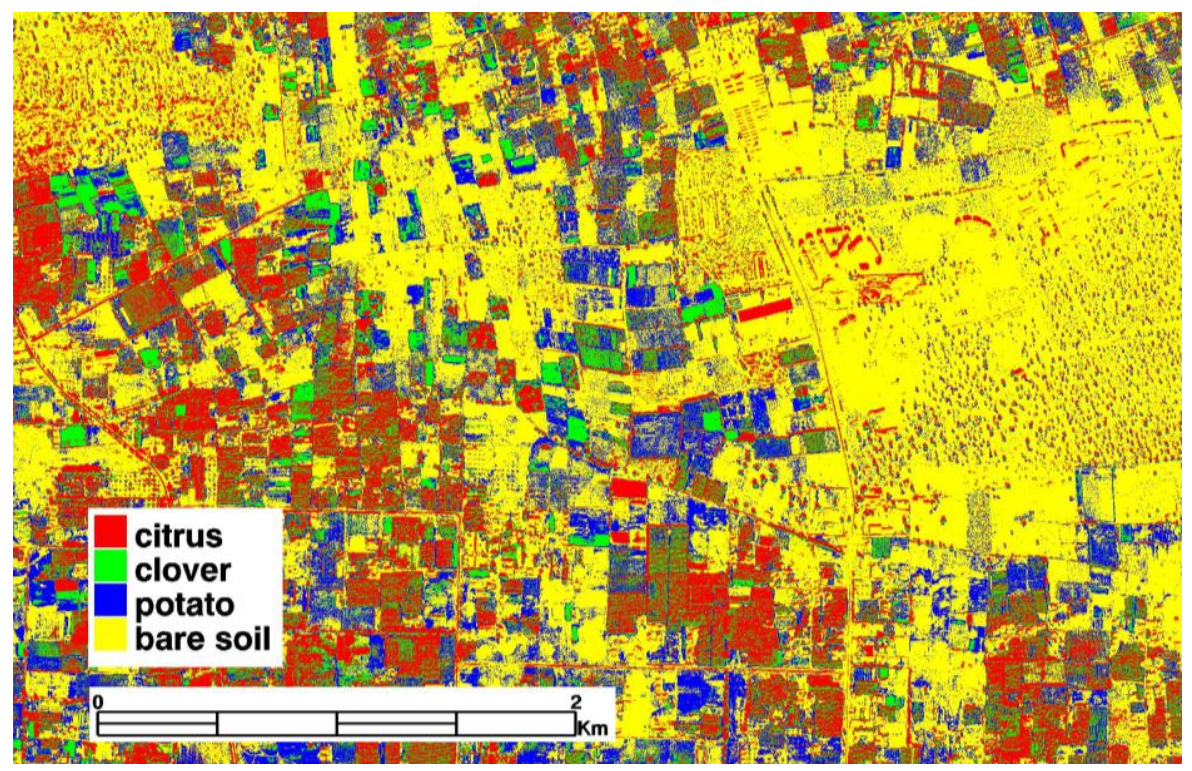


Figure 1 MD of GeoEye-1 image acquired on $21^{\text {st }}$ November 2010 for different crops in south Tripoli, Libya.

The results of the confusion matrix derived for MD algorithm is detailed in Table 3. The overall classification accuracy is high (92\%) associated with high kappa coefficient (0.89). The results showed high classification accuracy for different classes, ranging from $67.32 \%$ (for classifying citrus) to $97.63 \%$ (for classifying bare soil). The high classification accuracy of bare soil could be attributed to the pure pixels used in the ground truth data sets and also to the percent of vegetation to bare soil. It is obvious in the image that nearly half of the land mass is bare soil (40.87). These results are in full agreement with those obtained by Elmetwalli et al., 2010. They documented that Maximum Likelihood and Minimum Distance Classification algorithms are comparable to k-means unsupervised algorithms in identifying agricultural crops.

Table 2 Confusion matrix results for k-means algorithm of potato and other crops in south Tripoli, Libya.

\begin{tabular}{lccccc|c}
\hline Class & \multicolumn{5}{c|}{ Ground truth (Percent) } & \multirow{2}{*}{ User's } \\
& Citrus & Clover & Potato & Bare & Total & Accuracy \\
& & & & soil & & \\
\hline Citrus & 66.83 & 29.10 & 2.48 & 2.07 & 14.04 & 73.49 \\
Clover & 31.50 & 70.37 & 2.31 & 0.93 & 10.80 & 45.39 \\
Potato & 1.67 & 0.53 & 92.24 & 4.47 & 23.37 & 88.17 \\
Bare soil & 0.00 & 0.00 & 2.97 & 92.53 & 51.79 & 98.72 \\
total & 100.00 & 100.00 & 100.00 & 100.00 & 100.00 & \\
\hline Producer's & 66.83 & 70.73 & 92.24 & 97.63 & & \\
Accuracy $(\%)$ & & & & & \\
\hline Kappa & $\mathbf{0 . 7 9}$ & & & & \\
Coefficient & & & & & \\
Overall & $\mathbf{0 . 8 6}$ & & & & \\
Accuracy & & & & & \\
\hline
\end{tabular}


Table 3 Confusion matrix results for MD algorithm of potato and other crops in south Tripoli, Libya.

\begin{tabular}{|c|c|c|c|c|c|c|}
\hline \multirow[t]{2}{*}{ Class } & \multicolumn{5}{|c|}{ Ground truth (Percent) } & \multirow{2}{*}{$\begin{array}{c}\text { User's } \\
\text { Accuracy }\end{array}$} \\
\hline & Citrus & Clover & Potato & $\begin{array}{c}\text { Bare } \\
\text { soil } \\
\end{array}$ & Total & \\
\hline Citrus & 67.32 & 12.09 & 1.29 & 0.00 & 14.25 & 92.80 \\
\hline Clover & 30.59 & 87.91 & 7.14 & 0.18 & 13.27 & 46.49 \\
\hline Potato & 1.74 & 0.00 & 89.58 & 2.18 & 14.00 & 88.27 \\
\hline Bare soil & 0.35 & 0.00 & 1.98 & 97.63 & 58.48 & 99.41 \\
\hline Total & 100.00 & 100.00 & 100.00 & 100.00 & 100.00 & \\
\hline $\begin{array}{l}\text { Producer's } \\
\text { Accuracy (\%) }\end{array}$ & 67.32 & 87.91 & 89.58 & 97.63 & & \\
\hline $\begin{array}{l}\text { Kappa } \\
\text { Coefficient }\end{array}$ & 0.890 & & & & & \\
\hline $\begin{array}{l}\text { Overall } \\
\text { Accuracy }(\%)\end{array}$ & 91.77 & & & & & \\
\hline
\end{tabular}

\section{Association between vegetation indices and potato properties}

The $17^{\text {th }}$ September SPOT image was used to derive different vegetation indices and relate them to potato properties. Due limited number of spectral bands (blue, green and red only) the radiance at each band was used for this relationship. The results showed weak relationship between both chlorophyll content and tuber yield and the radiance at different regions of the spectrum. The ten tested broad band vegetation indices derived from the $21^{\text {st }}$ GeoEye- 1 satellite imagery data established strong relationships with properties of potato including chlorophyll content, and tuber yield (Table 4). The results at different locations demonstrated that vegetation indices successfully showed the potential of predicting biophysical and biochemical properties of potato. NDVI, SAVI and VARRI derived from the Geo-Eye satellite image produced the strongest correlation with the measured chlorophyll $(\mathrm{r}=0.77)$. The other tested vegetation indices produced strong correlations with the chlorophyll content $(r>0.70)$. Among the tested indices, DVI produced the minimum correlation coefficient $(\mathrm{r}=0.71)$. The results also demonstrated strong correlations with the tuber yield of potato. RVI and NDVI produced the highest correlation with the measured potato tuber yield $(r=0.76)$. DVI 
also produced the minimum correlation coefficient with the measured potato tuber yield.

It is obvious from the above mentioned results that GeoEye-1 satellite imagery successfully mapped the spatial variability of chlorophyll content which is closely linked to crop yield. These results are in agreement with those obtained by Yang et al., 2006a. Potato tuber yield can therefore be predicted using such high resolution satellite imagery. Successful mapping of agricultural crops at early stages will provide a reliable tool to detect areas suffering from stress and therefore take informed decisions to avoid yield reductions and thus maximizing yield productivity. Avoiding crop stress in arid and semi arid regions such as Libya may increase crop productivity that is important to sustain the rapid population growth. The results further demonstrated that GeoEye-1 image has low spectral capabilities and subsequently high spectral resolution imagery (Hyperion) would be effective imagery in detecting stress and distinguishing sources of stress at a regional scale since it provides images at $400-2500 \mathrm{~nm}$. Using this imager with the new advances in detectors, optics and electronics could acquire images with 220 spectral bands and thus calculating both broad band and hyperspectral vegetation indices.

Table 4 Coefficient of correlation between vegetation indices derived from the $21^{\text {st }}$ November GeoEye-1 and chlorophyll and tuber yield of potato in south Tripoli, Libya.

\begin{tabular}{|c|c|c|c|c|c|c|c|c|c|c|}
\hline \multirow{2}{*}{$\begin{array}{c}\text { Crop } \\
\text { property }\end{array}$} & \multicolumn{10}{|c|}{ Vegetation indices } \\
\hline & RVI & SI & NDVI & GNDVI & DVI & IPVI & VI1 & RDVI & VARI & SAVI \\
\hline Yield & 0.76 & 0.77 & 0.77 & 0.74 & 0.73 & 0.76 & 0.74 & 0.76 & 0.77 & 0.77 \\
\hline Chlorophyll & 0.76 & 0.76 & 0.76 & 0.75 & 0.71 & 0.76 & 0.75 & 0.75 & 0.76 & 0.76 \\
\hline
\end{tabular}

The results demonstrated that NDVI showed a strong index for predicting the concentration of Chlorophyll and potato tuber yield. Regression analysis was performed to derive regression equations for the relationship between NDVI and both properties as shown in Figures 2 and 3. Both figures show a positive significant relations between NDVI and both chlorophyll and potato tuber yield $\left(r^{2}=0.59\right.$ and 0.6 respectively). 


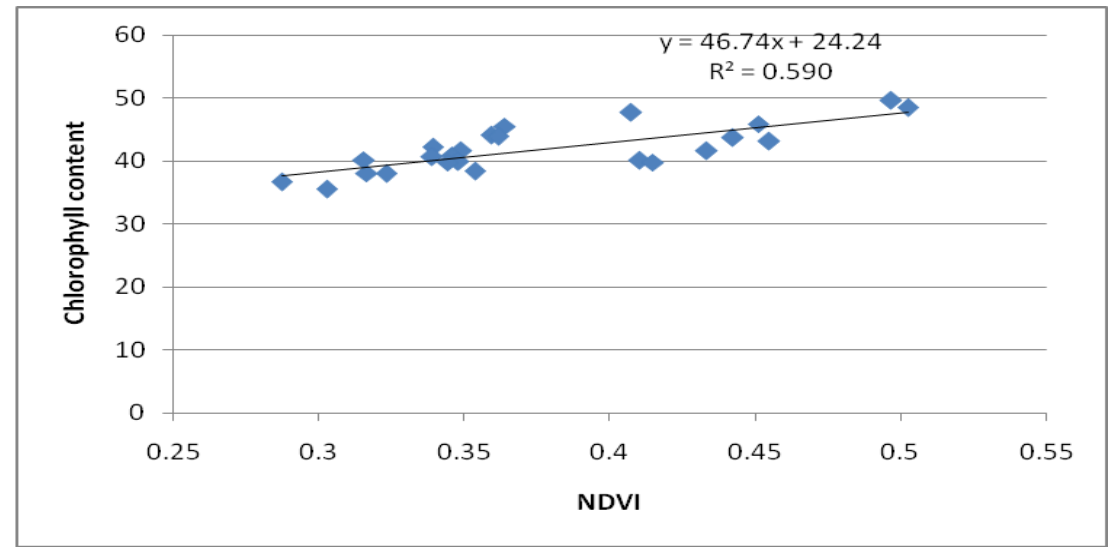

Figure 2 the relationship between NDVI derived from GeoEye-1 image and tuber yield of potato.

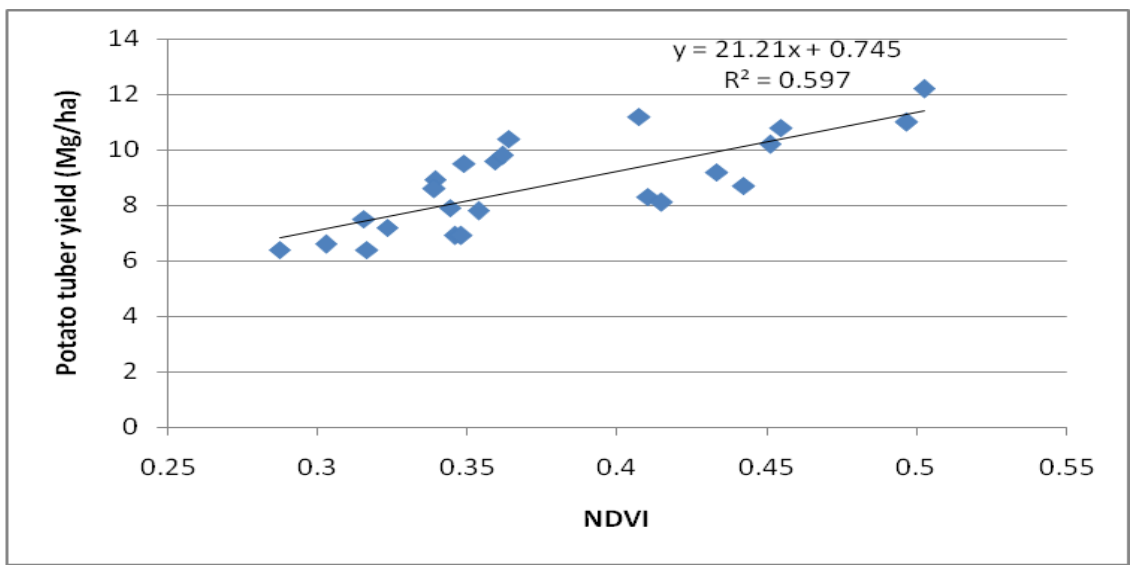

Figure 3 the relationship between NDVI derived from GeoEye-1 image and chlorophyll content of potato.

\section{SUMARY AND CONCLUSION}

It is obvious from the results of this research that GeoEye-1 high spatial resolution satellite remote sensing images can give a better understanding about stress at a local scale. GeoEye-1 imagery demonstrated the ability to predict potato crop properties including tuber yield, and chlorophyll content. Due to limited spectral resolution of GeoEye-1 satellite images (four spectral bands), it is difficult to distinguish nitrogen deficiency from water deficiency and therefore high spectral resolution imagery such as Hyperion is needed to identify wavelengths or narrow spectral 
regions sensitive to specific stressors. Using this technique in Libya will maximise the efficiency of water use and decrease input costs of fertilizers. Remote sensing can therefore be used as a useful, quick and cost-effective tool in precision farming and regional analysis giving timely information about crops in specific areas.

\section{REFERENCES}

Bannari, A., Khurshid, K. S., Staenz, K. and Schwarz, J. (2008). Potential of Hyperion EO-1 hyperspectral data for wheat crop chlorophyll content estimation. Canadian Journal of Remote Sensing 34: 139157.

Elmetwalli, A. H., Derbala, A. A. and Fouda, T. Z. (2010). Using in situ hyperspectral measurements and high resolution satellite imagery to detect stress in wheat in Egypt. Misr J. Agric. Eng., 27(4): 18111822.

King, B., Stark, J., Love, S. (2003). Potato production with limited water supplies. Idaho Potato Conference, January 22, 2003.

Moran, M. S. (2000). New imaging sensor technologies suitable for agricultural management. Aspects of Applied Biology, 60. Remote Sensing in Agriculture, 1-10.

Patel, N. and Rajput, T. B. S. (2007). Effect of drip tape placement depth and irrigation level on yield of potato. Agricultural water management, 88: 209-223.

Shock, C. C., Feibert, E. B. G. (2000). Deficit irrigation of potato. Deficit Irrigation Practices, Water Report 22, ISBN 92-5-104768-5, 109 pp.

Wu, J., Wang, D. and Bauer, M. E. (2007b). Assessing broadband vegetation indices and QuickBird data in estimating leaf area index of corn and potato canopies. Field Crops Research 102: 33-42.

Wu, J., Wang, D., Rosen, C. J. and Bauer, M. B. (2007a). Comparison of petiole nitrate concentration, SPAD chlorophyll readings, and QuickBird satellite imagery in detecting nitrogen status of potato canopies. Field Crops Research 101: 96-103.

Yang, C., Everitt, J. H. and Bradford, J. M. (2006a). Comparisons of QuickBird satellite imagery and airborne imagery for mapping grain sorghum yield patterns. Precision Agriculture 7: 33-44.

Yang, C., Everitt, J. H. and Bradford, J. M. (2006b). Evaluating highresolution QuickBird satellite imagery for estimating cotton yield. Transactions of the ASABE 49 (5): 1599-1606. 
Yoder, B. J., and Pettigrew-Crosby, R. E. (1995). Predicting nitrogen and chlorophyll content and concentrations from reflectance spectra (400-2500 nm) at leaf and canopy scales. Remote Sensing of Environment, 53: 199-211.

Zvomuya, F., Rosen, C. J., Russelle, M. P. and Gupta, S. C. (2003). Nitrate leaching and nitrogen recovery following application of polyolefin-coated urea of potato. J. Environ. Qual., 32: 480-489.

\section{الملخص العزبي}

استخدام صور الأقمار الصناعية عالية الاقة الايضاحية فى التنبؤ بالاجهاد على البرئ

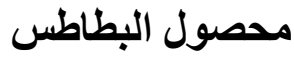

\section{عادل المتولى* طارق فودة*** الطاهر يوسف البط}

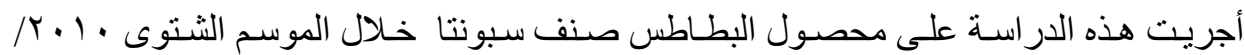

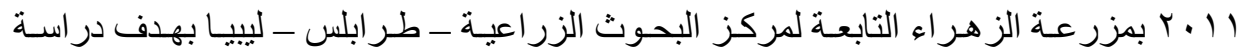

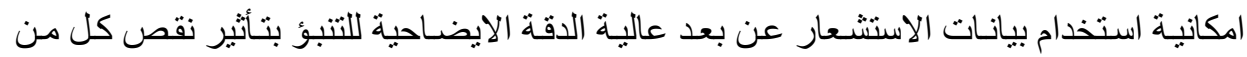

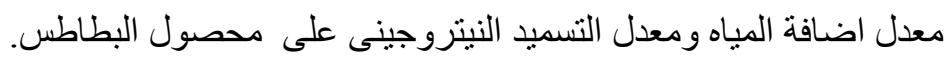
وقد صمدت التجربة بنظام القطع المنثقة حيث كانت معاملات الرى فئى القطع الرئيسية بينما

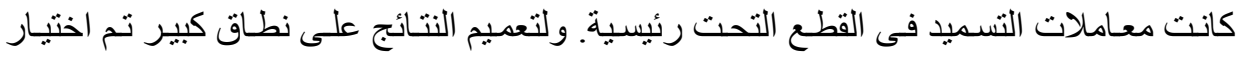

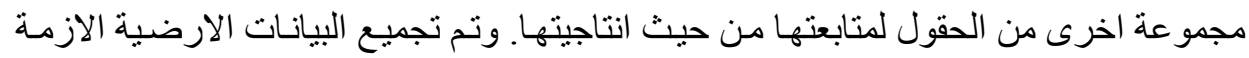

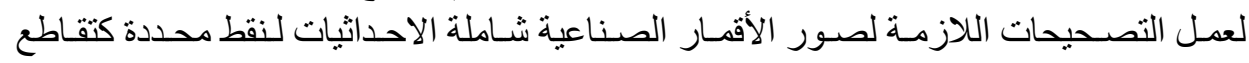

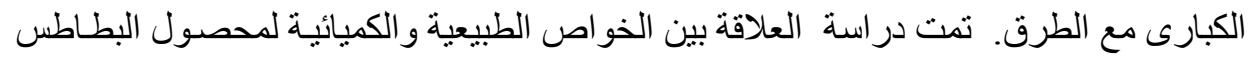

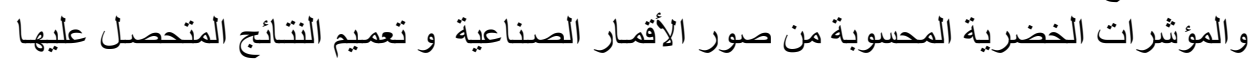

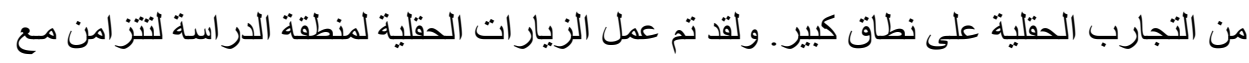

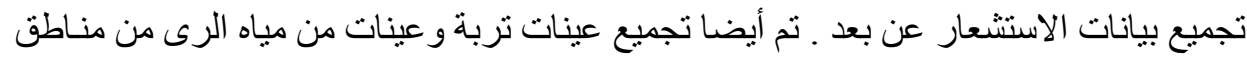

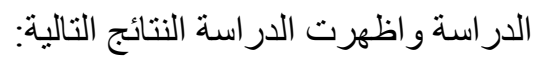

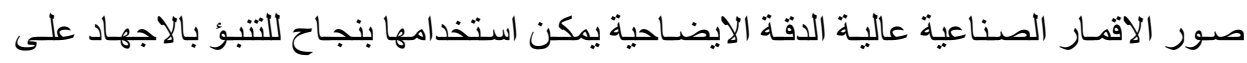

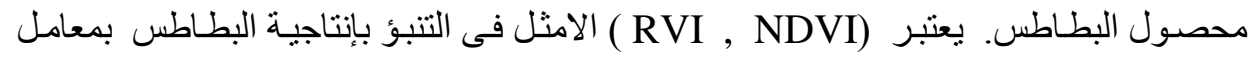

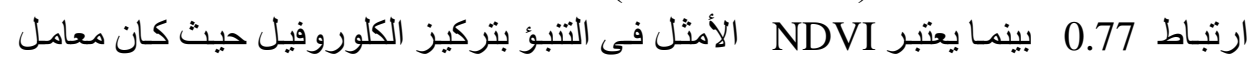

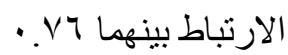

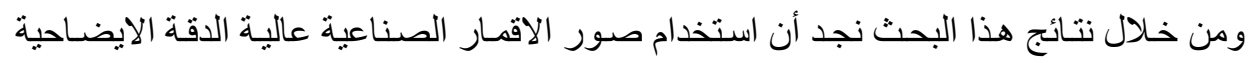

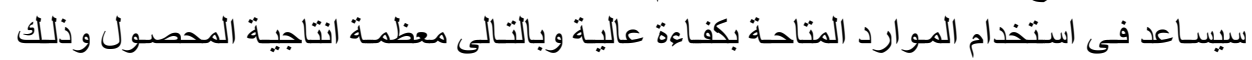
بالتنبؤ بالاجهاد على النبات عند مر احل نمو مبكرة واتخاذ القرار المناء المناسب لتجنبه.

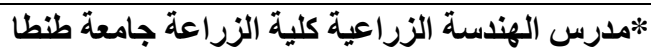

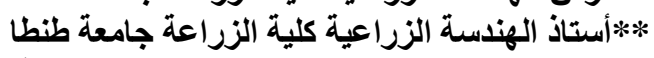

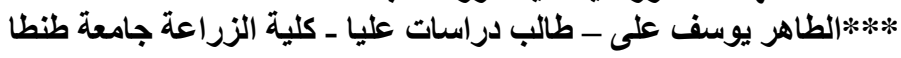

